\title{
The Evolution of Media and New Developments of Internet Literature
}

\author{
Luo Xin
}

Xi'an Fanyi University, Xi'an, Shaanxi710105, China

Key Words: internet media; traditional literature; internet literature.

\begin{abstract}
With studies on the relationship between the evolution of media and the development of literature, the role which media plays in the development of online literature was analyzed. The booming of internet has not only changed the way in which literature works were read and broadcasted, but exerted a gradual impact on the production of literature. As an integral part of the internet ecology, media was not only a tool by which culture is produced and broadcasted, but also a big factor behindthe genres, styles, coverage and the ways in which itworked on social reality of literature.
\end{abstract}

When artistic thinking is just an idea in your mind, no matter how novel, marvelous or integrated it might be, it can't be deemed as a work in any general senses. The reason why anartistic thinking can be turned into an artwork and finally accepted by the mass is the artistic carrier. In a sense, there is only artworks whereas no art. As a type of character art, literature needs media for its solidification and diffusion.After being finished by the writer,a literary workhas to go through a slew of procedures, including being published orreleased by the press, before it finally appeared in front of readers. And throughout the whole duration of artistic production, a course that any single literature work cannot bypass or shun, the media plays the most significant role.

As of the end of last century, three revolutions had been successively appeared in the communication history of human beings, namely the birth of verbal communication, the creating and use of characters and the invention of wireless telecommunication.

During the period of the first revolution, verbal literature came into being. With verbal languages and reciters of poetry as the transmitting vector, this kind of literature such asmasterpiecesof the Classics of Poem·Guofeng,Homer's Epic and numerous folk songs, waspassed by people.Written literature and published literature born during the second revolution. Similar in creation, the two literatures are both more delicate, exquisite and charming than the verbal literature. However, they bear a distinct difference from each other in terms of the transmitting vehicle. With merely words, paper and pens as the media, written literature is in a sense a pure literature. Meanwhile, invariably affected by publishers, editors, critics and market, published literature, especially for those oriented to the mass, seems more like commercial literature. After the third revolution, the radio technology has led to electronic media literature, including radio, film and television literature. Although being called literature, this newly born literature has not formed a specialized genre, or left any substantial influences over the literature creation. In this connection, it failed to function as a real literature. And written literature and published literature are still considered as the main stream and model literature which symbolize other forms of literature. Consequently, the impact of media technology and devices over literature was neglected for a long time.

As early as in the middle of last century, with studies of the relationship between the transformation of media and modern literature, Canadian communication scholar Marshall McLuhan pointed out that”Media Is Message”. Decades later, Eric McLuhan, the son of Marshall McLuhan, added that” Media will change everything. Like it or it, it will surely introduce a new 
culture meanwhile bring an end to an old one."Although the decisive role of media over literature remains to be discussed, it will undoubtedly affect the semiotic character, symbolic character and the mentality of readers. From verbal literature to electronic media literature, from pure literature to commercial literature,

We have no difficulty finding the imprints of media throughout the development of literature.Does that mean a new form of literature will be born in the course of the contemporary internet technological revolution?

No matter of Daniel Bell's Theory of Postindustrial Society, The Third Wave by Alvin Toffler or The Great Tendency by JhonNaisbitt, wise heads all predicted that: knowledge and information will become the major features of the future society. The prophecy came true. After the beginning of 21st century, Internet became the synonymous with informational society. According to The 38th Accounting Report of Chinese Internet Development(The Report Hereinafter) by CNNIC, as of the June of 2016, the number of Chinese citizens climbs to 710million, with a record high of 51.7\% internet popularizing rate.That means internet is dramatically changing our life in every respective.

For literature-fans, internet serves as a relaxing platform on which creation and reading could be done without worries of genres, style formats, wording and phrasing, and free from watchdogs, mind-boggling fees and even siting in square while reading books.Based on online read and writing platform, Online Literature rises. Only one decade later, the number of the online literature equals the gross of published literature of more than 60years after the founding of new China. According to reports, the number of Chinese online internet users reached 308 million, with $43.3 \%$ internet usage of online literature.

Internet literature refers to "original literary works which were firstly released online”. Due to a different media, it is quite distinctive when being compared with main stream literature or traditional literature.

First, the non-specialization and non-elitism of writers

Traditional writers were mainly literature-fans, who receivedvarious forms of training, such as learning from good teachers and participating in top competitions. And more importantly, they write within the systems, including writer's associations and literary periodicals. As such, we name them as "writer", together with professionaleditors, they are regarded asdisseminators of traditional literature.On the contrary, the threshold of internet literature is not that high. Practitioners in this field come from all walks of life, including students, civil servants, even security and farmer workers. Jiang Zilong(1941-, Chinese writer) once concluded this new form of literature as "the literature without origin", he noted that "the writers of internet literature is a writing group that is most powerful, mixed, vigorous and spotty." For these people who dedicated themselves to this sector, we get used to calling them "network writers".

Second, the diversification of contents and ambiguity of genres

The column setting of People's literature,an representative medium of traditional literature, contains medium-length novels, short novels, modern documentary fictions, poem and poetics, poetry of youth, latest poems, elected essays, etc. Meanwhile, the column setting of qidian.com, a major players in internet literature section, range from fantasy, strange, martial arts, supernatural fictions, city novels to workplace, military, history, game, sports, science and ghost novels. We can easily find that in the People's literature, different genres of literature were highly classified. However, as manifested by qidian, the boundaries between genres were quite ambiguous. Moreover, the multitudes of column names reflect the diversification, materialization and secularization of internet literature. Some people praised traditional literature as "the elite reading of paper writing." One single meaning of the word "elite" was the elite standpoint. With elaborate conceptions of 
writers, strict checks of editors and timely releasing of media, traditional literature works, overtly or covertly, reflect important social values. With the elite standpoint, writers and professionals want these works to exert positive influences over the readers. In comparatively fixed genres, writers expressed their thinking of life, country and society. At the same time, the objects and contents of internet literature is far more varied. The connotation, thinking, standpoints of works and even the boundaries between genres were put aside. Jiang commented that "the expressing fashion of internet literature is a carnival of words...... r read a good many internet literature novels, only some of which could be understood. Anyway, its creation is still firing on all cylinders. ”

Although words were employed as the symbolic carriers of the two literatures, image also serves as another kind of carrier in online literature. What's more, traditional media such as pen, paper was replaced by screensof computer and cellphone, keyboards and mouses. The publishing sector was substituted by a click of "send". In the spreading activities of internet literature works, it is not published books but the virtual bridge of internet connectingbetween readers and writers.

Fourth, the generalization of readers

Since the carriers of traditional literature are mainly periodicals and books, which need to hit the market to realize communication. That means readers, who are mainly literary enthusiasts, have to pay for the pleasure of reading. On the contrary, online readers have to do nothing but looking for their ideal fictions and novels. In the meantime, many of the internet readers log into literature websites simply because of these alluring headlines. Therefore, this readers group is far more mixed, mobile and random than the one of traditional literature.

With regard to the communicating effect, circulation and hits were respectively two criteria of the two literatures. In 2007, online novel the Adventure of Zhao Ganlv worked a miracle of 100 million hits after being posted. According to the standards of bestseller, originated in U.S,a bookwitha weekly sale of more than 40,000 or a monthly sale of more than 15,000 could be defined as a bestseller. Whether these works are literary works or not, the gap of numbers is hard to bridge for traditional literature. Except hits, the powerful communication effect of internet literature also manifested by feedback from and interaction with readers. Thanks to the instantaneity of internet, readers could send their impression of view and other ideas of the work to the writer through comments and following post, and the writers could correspondingly adjust their works in terms of plots, lengths of chapters or sets of characters. In this sense, compared with the top-down fashioned traditional literature, internet literature is more timely and active in terms of feedbacks and interactions.

The factors behind the overt characteristics of internet literature can be found in the theory of McLuhan. Same as the previous three revolutions, in the era of internet, keyboards, mouse and typewriting software, such as Sougou, IMEs and Wubi, transformed the traditional writing models. And this change of input tools also marked a great leap of creation ideas and subjects' capability. Nowadays, the whole spreading process of writing, from material accumulating, breaking and remarking to publication and distribution, was greatly simplified with the help of internet technology. Maybe the “Double Acting Models” of Bass doesn't work today, because the internet has taken place of processors of information. Without these barriers, the wealthy white-collars churned out a bunch of works by whim to release their moods. With merely screen names, they produced a good many novels and fictions filled with romantics, online loves and bourgeois sentiments. Another major part of internet writers is the group of students who are good at internet technologies and passionate about creating. With just common senses of literature, they love high accessible literature and fast-food style expressions. Hence, the elitism was eventually erased in internet literature. In spite of various themes and unusual genres, readers immediately post their 
comments and ideas and join in discussion. Based on the feedbacks from readers, writers could reorient their works. The desire of adding their own thoughts to their fancy books generated hits of 1 million times. Like domino effect, the development of internet technology is unstoppable.

As a critic once said: “ If we had continued keeping tallies by typing knots in ropes, there would be no algebra, if there was no invention of paper, there would be no long-length novel.” It seems that communicating media, especially internet, have made a profound change of our ways of reading, writing and thinking. It also means that internet has not only transformed communicative methods, but also reshaped genres and styles of literary works, and even the ecologies of our society and literature.

\section{Acknowledgement}

This is a Shaanxi Educational Department Scientific Research program which belongs to "The Study on the Broadcasting Methods of TV Brand and the Shaping of Folk Culture of Shaanxi Province"(15JK2038), also an Art Programming Item of Shaanxi Social Scientific foundation which belongs to "The Study on the Broadcasting Methods and Strategies of Shaanxi Elements in Shaanxi Films and Media”(2015SY055).

\section{References:}

[1] Marshall McLuhan, He Daokuan. Man’s Extension [M].Beijing: The Commercial Press, 2005.

[2] Eric McLuhan, Frank Zingrone, He Daokuan. The Essence of McLuhan’s Thinking [M]. Nanjing University Press, 2000.

[3] CNNIC. The $38^{\text {th }}$ Accounting Report of Chinese Internet Development [EB]. 2016.8.3.

[4] Nan Fan. Double Horizons - An Analysis of Contemporary Electronic Culture [M]. Nanjing: Jiangsu People’s Press, 2001.

[5] NieZongpu. Network Narration [M]. Beijing: Chinese Culture Union Press, 2004.

\section{【Introduction】}

LuoXin(1981.12-), born at Xi'an, Shaanxi province, art master degree. As a lecturer of journalism and communication, Ms Luo is mainly engaged in communications and film literature. 